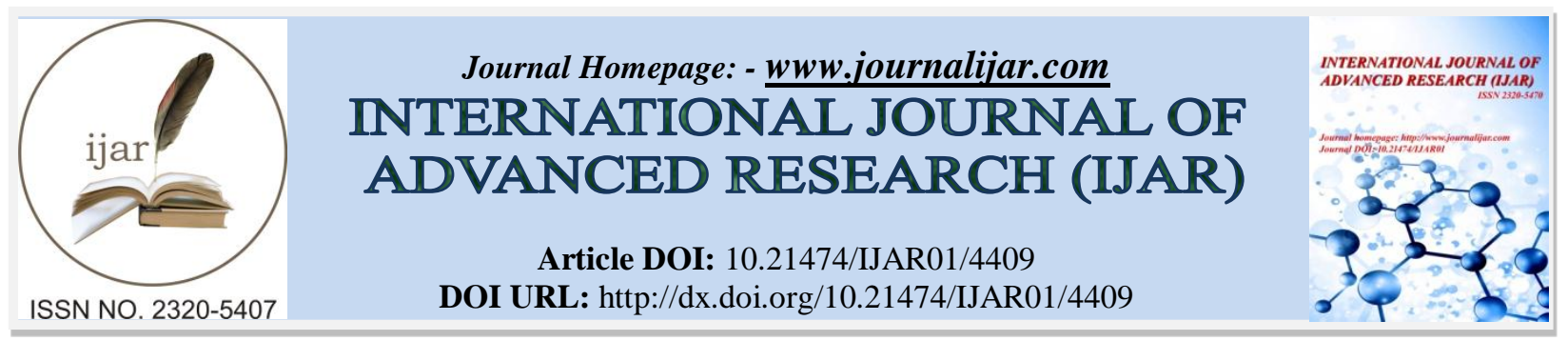

RESEARCH ARTICLE

\title{
MANAGEMENT OF FEMALE INFERTILITY W.S.R. TO ANOVULATION WITH UNANI FORMULATION - CASE SERIES.
}

Kafeel Ghazia and Shameem Ismath.

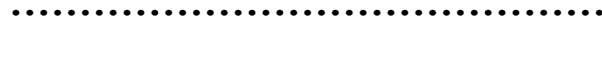 \\ Manuscript Info \\ Manuscript History}

Received: 07 April 2017

Final Accepted: 09 May 2017

Published: June 2017

Key words:-

Anovulation, unani medicine, hab hamal.

\section{Abstract}

Rise in number of infertile couple is a major concern worldwide. More and more number of male and female are prone to infertility in cities due to life style. Anovulation is responsible for $30-40 \%$ of infertility. It is recommended that the administration of ovulation inducing agents be carried out only when they are indicated in order to achieve pregnancy rates without increase in untoward side effects. The first line of treatment in conventional medicine for induction of ovulation is use ofovulation inducing drugs. However, therapy may cause side effects like increased risk of ovarian hyperstimulation, abortion, multiple pregnancies etc and are contraindicated in liver dysfunction, breast diseases, $\mathrm{h} / \mathrm{o}$ severe side effects etc; hence this treatment may not be suitable in all cases. Therefore, the number of couples turning to technologies and artificial methods like IVF (In Vitro Fertilization) is increasing. Due to the high cost of ART procedures, it is beyond the reach of some patients hence finding an alternative therapy has been always in the need. In classical unani literature, various formulations has been mentioned for the treatment of uqr, possessing the properties like muqawwi rehm, moaene hamal, moallide mani which are to be used from the 5th day of menstrual cycle (corresponds to ovulation inducing drugs) as conception is most likely to take place after menstruation. Such types of drugs are known to contain phytoestrogens and may induce ovulation by maintaining hormonal balance therefore present case study has been done by using hab hamal (unani medicine) in anovulatory patients.

Copy Right, IJAR, 2017,. All rights reserved.

Ovulation is the central event in female reproduction ${ }^{1}$ Coordinated effects of hypothalamic gonadotropin releasing hormones, pituitary gonadotropins, ovarian estrogens and follicular response to these effects result in ovulation. Any derangement of the above factors results in ovarian dysfunction. ${ }^{2}$ Today nearly $30-40 \%$ of infertile patients suffer from ovulatory dysfunction ${ }^{2}$ in which $75 \%$ have polycystic ovaries and 20 to $25 \%$ of women with normal ovulation; demonstrate ultrasound findings typical of polycystic ovaries. ${ }^{3}$ Anovulation can be a feature of hypothalamic anovulation, hyperprolactinaemia, polycystic ovaries, luetinised unruptured follicles and luteal phase deficiency. ${ }^{2}$

In majority of these women, the disorder of ovulation is obvious because there is a complete lack of menstruation (primary or secondary amenorrhoea) or infrequent menstruation (oligomenorrhoea) Therefore the exact prediction of ovulation is important in many infertile women. Until recently, treatment was largely empirical and resulted in disappointing conception rates, but a diagnosis with accurate therapeutic implications can now be reached in most 
patients. ${ }^{4}$ The availability of drugs to induce ovulation has been one of the most significant advances in the treatment of infertility in the past 25 years. ${ }^{3}$ As neuroendocrinology and ovarian physiology has advanced, new ways of restoring normal physiology with the induction of ovulation have appeared and thus, the choice of the correct agent for the induction of ovulation is dependent upon a specific diagnosis. Until recently, treatment was largely empirical and resulted in disappointing conception rates, but a diagnosis with accurate therapeutic implications can now be reached in most patients. ${ }^{4}$ Of all the infertility factor, disorder of ovulation has the widest range of treatment armamentarium. It is recommended that the administration of ovulation inducing agents be carried out only when they are indicated in order to achieve pregnancy rates without increase in untoward side effects. ${ }^{5}$ The first line of treatment in conventional medicine for induction of ovulation is use of clomiphene citrate therapy for 5 days after menstruation. However, clomiphene citrate therapy may cause side effects like increased risk of ovarian hyperstimulation, abortion, multiple pregnancies etc and are contraindicated in liver dysfunction, breast diseases, h/o severe side effects etc. There has been a broad description of infertility in unani system of medicine also. In classical unani literature infertility has been mentioned centuries back and defined as when conception fails to occur or when there is a difficulty in conception either due to the defect in male or female partner. Defect in female partner are attributed to the diseases of ovaries (aazae mani), uterus (rehm) or idiopathic. There are various causes of female infertility as mentioned in unani literature. According to Unani physicians, if the cause of infertility is in female gamete (ovum), it is either due to qillate maddae manwia (anovulation) or fasaad mani (dysovulation). The defect in ovum is attributed to sue mizaj barid which solidifies the mani leading to infertility. ${ }^{6,7,8,9,10}$ Hippocrates has mentioned that defect can occur in both male mani (sperm) and female mani (ovum). ${ }^{7,8,9}$ Other causes of female inferiltiy includes defects in ovaries like warm khusiyatur rehm (oophoritis) ${ }^{10}$, menstrual irregularities ${ }^{14,15,16}$, defects in uterus like metritis, inversion of uterus, prolapse of uterus (Warm rehm, Mailan rehm, Inqalabur rehm ) and Congenital defects of uterus . General causes include obesity (samne mufarrat) disease of other organs (Aaze shareefa wa rayeesa) such as disorders of nervous system and brain (Zoaf dimagh), cardio vascular system (Zoaf qalb) , liver disorders (Zoaf jigar), anxiety and stress (Khouf, Gham) anaemia( Sou ul quniya) $6,7,8,9,10,11,12,13,14,15,16,17,18,19$. In classical unani literature, various formulations has been mentioned for the treatment of anovulatory infertility, possessing the properties like uterine tonic (muqawwi rehm), moaene hamal, ovulation inducing drugs (moallide mani) which are to be used from the 5th day of menstrual cycle (corresponds to ovulation inducing drugs). ${ }^{6,7,20}$ Such types of drugs are known to contain phytoestrogens and may induce ovulation by maintaining hormonal balance. ${ }^{13}$ Unani formulation may induce ovulation by ovulation (increasing maddae manwia) and result in conception as it is helpful in conception (moaene hamal): hence beneficial in cases of anovulatory infertility. $11,12,13,14,15,16,17,18,19,20$ The main objective of the study is to explore the efficacy of unani formulation scientifically for treatment of anovulation.

\section{Case History 1:-}

A 23 year old female, registration no 00436, visited the OPD of National Institute of Unani Medicine, Hospital , Bangalore nium hospital with history of primary infertility since 3 years for the first time on 15/10/2009 . She had infrequent menstrual cycles occurring at 2-3 months only on induction with moderate flow. General examination reveals moderate hirsuitism, mild acne, acanthosis nigricans was also present.

\section{Examination:-}

Per speculum - No vulvitis, No vaginitis, cervix mild erosion mild vaginal discharge External os - Nulliparous Per vaginum - Uterus Anteverted, Normal size / Fornices Free, mobile.

Pregnancy test was negative therefore she was induced menstruation with unani drugs on 12 february 2010. Menstruation occurs on 28 feb 2010.

\section{Investigations:-}

Baseline investigations such as complete blood picture with ESR, random blood sugar and urine examination were with in normal limits.

Patient was evaluated for the patency of fallopian tubes and anovulation. Patient was advised hormonal profile on the second day of menstrual cycle in the fasting and HSG on $9^{\text {th }}$ day in the same menstrual cycle. Thyrid profile and $\mathrm{S}$. prolactin were in the normal limits.

LH:FSH was 3:1

HSG - both fallopian tubes were patent with normal shape size and position of uterus

Ultrasonography - follicular studys shows right ovary follicle size $13 \mathrm{X} 11 \mathrm{mmon}$ on $16^{\text {th }}$ and $18^{\text {th }}$ day of 
menstruation. Endometrial Thickness $-5.4 \mathrm{~mm}$. left ovary no dominant follicle with polycystic ovaries. Findings suggestive of anovulatory cycle.

S. progesterone done on $21^{\text {st }}$ day of menstrual cycle was $0.30 \mathrm{ng} / \mathrm{ml}$

Husband Semen Analysis: shows normal sperm count and motility.

\section{Treatment:-}

After required investigations the patient was diagnosed with anovulatory cycle compound formulation habbe hamal 1 tab twice daily with milk from the second day of next menstrual cycle for 5 days along with this majoon supari pak $7 \mathrm{gm}$ twice daily. Treatment was started on 1/6/2010 for Ist cycle with induction of menstruation by unani drugs. Menstruation occurs itself on 12/07/2010. Again in this cycle treatment was repeated. Menstruation occurs by itself on 22/08/2010. Treatment was started for the third cycle.

\section{Results:-}

Patient came with 42 days amenorrhoea on 4/10/2010 with c/o morning sickness. Urine pregnancy test was conducted at hospital and found positive. Ultrasonography reveals an intrauterine gestation sac. Patient took proper antenatal care and delivered healthy child full term.

\section{Case History 2:-}

A 29 year old female Mrs GN with OPD registration no 122525 visited the National Institute Of Unani Medicine, Hospital , Bangalore with history of primary infertility since 2 years for the first time on 25/1/2010. She had regular menstrual cycle of 24-25 days with scanty flow since one and half years with LMP- 06/1/2010. General examination reveals no hirsuitism, no acne, no acanthosis nigricans. Per speculum shows no vulvitis, no vaginitis, cervix was conical and healthy, external os was nulliparous. Uterus was retroverted, normal size, Fornices free on per vaginum examination. Family history of thyroid dysfunction was positive.

\section{Investigations:-}

Baseline investigations such as complete blood picture with ESR, random blood sugar and urine examination was done which was normal. Patient was evaluated for the patency of fallopian tubes and ovulation disorder. Patient was advised hormonal profile on the second day of next menstrual cycle in the fasting and Hysterosalpingography (HSG)on $9^{\text {th }}$ day in the same menstrual cycle .Hormonal profile includes S.FSH, S.LH, Thyrid profile and S. prolactin were in the normal limits. HSG - both fallopian tubes were patent with normal shape size and position of uterus Ultrasonography - follicular study shows Left ovary follicle size $13 \mathrm{X} 13 \mathrm{mmon}$ on $16^{\text {th }}$ day of menstruation. Endometrial Thickness $-6 \mathrm{~mm}$. Right ovary no dominant follicle.Findings suggestive of anovulatory cycle.

Husband Semen Analysis: shows normal sperm count and motility.

\section{Treatment:-}

After required investigations, treatment was initiated on 5/05/2010 with the compound formulation on hab hamal 1 tab twice daily with milk from the second day of menstrual cycle for 5 days along with this Majoon supari pak 7 gm twice daily. Patient got menstruation on 3/06/2010. Again Treatment was started for the second cycle.

\section{Results:-}

Patient came with 40 days amenorrhoea on 12/07/2010. Urine pregnancy test was conducted at hospital and found positive. Patient took proper antenatal care and delivered male child full term.

\section{Case History 3:-}

A 28 year old female Mrs LA with registration no 014227 visited the OPD of National Institute Of Unani Medicine, Hospital , Bangalore with history of primary infertility since 4 years for the first time on 21/6/2010. Previously, she had regular menstrual cycle of 25-28 days with scanty flow but now since last 4 years since her marriage, her menstrual cycles were irregular occuring at 45-50 days with only spotting occuring for one day. There was no h/o thyroid dysfunction, diabetes mellitus, any chronic illness like koch disease. Her LMP was 8/06/10.

General examination reveals moderate hirsuitism, mild acne, no acanthosis nigricans no Glactorrhoea. Per speculum examination shows healthy cervix and per vaginum uterus was anteverted, normal size with fornices tender. 


\section{Investigations:-}

Baseline investigations such as Complete blood picture with ESR, random blood sugar, lipid profile, LFT, VDRL, HIV I\&II and urine examination shows no significant abnormality .Ultrasonography - shows bilateral polycystic ovaries ON 24/06/2010.

Husband Semen Analysis: shows total sperm count as 26 million per cumm with actively motile as $40 \%$ and sluggish motile as $35 \%$

\section{Treatment:-}

Treatment was initiated on 4/8/2010 with the compound formulation Hab Hamal 1 tab twice daily with milk from the second day of next menstrual cycle for 5 days along with majoon supari pak $7 \mathrm{gm}$ twice daily

\section{Results:-}

Patient came with 40 days amenorrhoea on 12/09/2010. Urine pregnancy test was conducted at hospital and found positive. Pregnancy was carried till term.

\section{Case History 4:-}

A 32 year old female Mrs PDN visited the OPD of National Institute Of Unani Medicine, Hospital , Bangalore hospital with history of primary infertility since one and half years for the first time on 31/1/2011. She had regular menstrual cycle of 28-30 days with moderate flow with LMP- 22/01/ 2011. General examination reveals no hirsuitism, no acne, no acanthosis nigricans. Examination: Per speculum shows no vulvitis, no vaginitis, cervix is conical and healthy, external os is nulliparous. Per Vaginum shows uterus shows anteverted uterus, mobile. Normal size and fornices free.

\section{Investigations:-}

Baseline investigations such as complete blood picture with ESR, random blood sugar, Lipid Profile, LFT, VDRL, HIV I AND II and urine examination. was done which reveals no abnormal findings. Patient was evaluated for the patency of fallopian tubes and ovulation disorder.HSG - both fallopian tubes were patent with normal shape size and position of uterus

Ultrasonography - follicular study shows Left ovary follicle size $6 \times 7 \mathrm{~mm}$ on $16^{\text {th }}$ day of menstruation. Endometrial Thickness $-6 \mathrm{~mm}$. Right ovary no dominant follicle.

Husband Semen Analysis: shows normal sperm count and motility

\section{Treatment:-}

Treatment was initiated with the compound formulation hab hamal 1 tab twice daily with milk from the second day of next menstrual cycle with LMP- 14/02/2011 for 5 days along with this majoon supari pak 7 gm twice daily.

\section{Results:-}

Patient came on 30/03/2011 with 45 days amenorrhoea. Urine pregnancy test was conducted at hospital and found positive. Pregnancy continued till term and delivered a healthy baby.

\section{Case History 5:-}

A 28 year old female Mrs SB with OPD registration no 005071 visited the OPD of National Institute of Unani Medicine, Hospital , Bangalore hospital for the first time on 9/05/2011. She complains of not able to conceive since 5 years. She had regular menstrual cycle of 24-25 days but with scanty flow since one and half years with LMP07/05/2011. There was no h/o diabetes mellitus, hypertension or any chronic illness like Koch disease. Married life was of 5 years. General examination reveals no hirsuitism, no acne, no acanthosis nigricans. Per speculum shows no vaginitis, cervix was healthy and External os was Nulliparous

P/V - Uterus - Anteverted, Normal Size, Fornices Free, firm and mobile .

\section{Investigations-}

Baseline investigations such as Complete blood picture with ESR, random blood sugar, lipid profile, VDRL, HIV I and II and urine examination were normal . Patient was further evaluated for the patency of fallopian tubes. Patient was advised hormonal profile on the second day of next menstrual cycle in the fasting and HSG on $9^{\text {th }}$ day in the 
same menstrual cycle .Hormonal profile include S.FSH, S.LH, Thyrid profile and S. prolactin were in the normal limits.Patient had follicular study done on 19/3/11 which reveals unruptured dominant follicle of $26 * 22 \mathrm{~mm}$ with POD free which were suggestive of anovulatory cycles.

HSG - both fallopian tubes were patent with normal shape size and position of uterus Husband Semen Analysis: shows normal sperm count and motility

\section{Treatment:-}

After required investigations the patient was diagnosed with anovulatory cycle and treatment was initiated with the compound formulation habbe hamal 1 tab twice daily with milk from the second day of next menstrual cycle for 5 days along with this majoon supari pak $7 \mathrm{gm}$ twice daily.

Patient came with H/O missed period with lethargic feeling on 15/07/2011. Urine pregnancy test was conducted at hospital and found positive. Patient took proper antenatal care and delivered female child full term.

\section{Discussion:-}

Hab hamal was found to be effective in the treatment of anovulatory infertility. Effect of habbe hamal can be attributed to the constituents present in this compound formulation. ${ }^{20,21}$ It contains papaver somniferum (Afiyun) $1.48 \mathrm{mg}$, Myristica fragrans (Jaiphal ) 44.98mg, crocus sativus ( Zafran) 12.68mg, cannabis (Bhang) $22.11 \mathrm{mg}$, old jaggery (Purana gurh) $69.50 \mathrm{mg}$, Areca catechu (Chalia) $214.50 \mathrm{mg}$ Eugenia caryophyllata (Laung) $4.40 \mathrm{mg} .{ }^{21}$ Macelignan is a natural compound isolated from M. fragrans. It enhanced the insulin sensitivity and improved lipid metabolic disorders by activating peroxisome proliferator receptor (PPAR, á/ã) and attenuating endoplasmic reticulum stress, suggesting that it is an antidiabetic agent for the treatment of type 2 diabetes (Han et al., 2008) ${ }^{22}$

In Unani medicine, M. fragrans (nutmeg) has been mentioned to be of value in the management of male and female sexual disorders. In an experimental study, Tajuddin et al. (2005) have found that the oral administration of 50\% ethanolic extract of nutmeg at $500 \mathrm{mg} / \mathrm{kg}$ body weight produces a significant and sustained increase in the sexual activity of normal male rats without any conspicuous adverse effects, which might be attributed to its nervous stimulating property. ${ }^{22}$ In a study conducted by Mokhtari et al have found that hydro-alcoholic saffron extract can promote the pituitary-ovary axis activities at all levels, cause an elevation in the serum concentrations of LH, FSH and estradiol hormones, as well as increase the mean numbers of secondary follicles and eventually ovarian weight. It is probable that these effects are the results of active compounds such as crocin, crocetin and saffranal, all of which are present in the extract. ${ }^{23}$ It can be suggested that one might use saffron to enhance fertility and treat infertility in females, although further studies are still required which is in accordance with the therapeutic effects mentioned in unani literature.

\section{Conclusion:-}

Hab hamal has been mentioned in the classical unani literature for the treatment of infertility. Based upon the above case studies, it is further recommended to have a clinical trial on a larger sample size in order to prove its efficacy in treatment of anovulatory infertility scientifically.

\section{Acknowledgement:-}

We are highly thankful to patients who were included in the study as well as staff of National Institute of Unani Medicine, Hospital.

No Conflict of interest.

\section{References:-}

1. Sengupta BS, Chattopadhyay SK, Varma TR. Gynaecology for Postgraduates and practioners. 2nd ed. New Delhi: Elsevier India (P) Ltd; 2007: 59-75, 111 , 128, 140-141,161-167.

2. Desai P, Malhotra N. Principles and practice of Obstetrics and Gynaecology. 3rd ed. New Delhi: Jaypee Brothers Medical Publishers (P) Ltd; 2008:676-735

3. Kumar P, Malhotra N. Jefffcoate's Principles of Gynaecolgy. 7th ed. New Delhi: Jaypee Brothers Medical Publishers (P) Ltd; 2008: 384-400,699-741

4. Devroey P, Fauser BCJM, Diedrich K. Approaches to improve the diagnosis and management of infertility. Oxford J Hum Reprod Update2009 Jul-Aug; 15(4): 391-408. 
5. Grace WKT. Seminars in Reproductive Technology: Recent Advances in Ovulation Induction. Journal of Hong Kong Medical Association 1987; 39(3): 141-143.

6. Majoosi ABA. Kamilus Sanaa (Urdu trans. by Kantoori GH). Vol I and IX. Lucknow: Munshi Nawal Kishore; 1889:39-40,155-158,344, 426-428; 498499,533,535.

7. Ibn Sina. Al Qanoon Fil Tib (Urdu trans. by Kantoori GH). Vol II. New Delhi: Idarae Kitabul Shifa; 2007:267304.

8. Ibn Rushd. Kitabul Kulliyat.2nd ed. New Delhi: CCRUM; 1987:28,114-118

9. Kabeeruddin S. Al Akseer. Vol II. New Delhi: Ejaz Publishing House; 2003: 1397-1401.

10. Ibn Zuhr. Kitabal Taiseer. Vol I. New Delhi: CCRUM; 1986:168-175.

11. Baghdadi IH, Kitab al mukhtarat Fit tib(urdu translation) Vol IV.New Delhi: CCRUM; 51-55.

12. Khan A. Haziq. Delhi: Madina Publishing Company; 1983: 461-464.

13. Quamri AMH .Ghana Mana (urdu translation) .New Delhi : CCRUM ; 2000 : 324-328.

14. Kabeeruddin M. Ifadae Kabeer. New Delhi: Qoami Council Barae Farogh Urdu Zaban; 2001: 100,169,170.

15. Kabeeruddin M. Kulliyat Qanoon(urdu translation). Vol I,II.Lahore:Sheikh Mohd Basheer and sons ; YNM:33$65,239-240$.

16. Hamdani KH. Usool Tib . 2nd ed. New Delhi: Qoami Council Barae Farogh Urdu Zaban; 2006: 228-300.

17. Ahmed SI. Introduction to Al-Umur Al-Tabiyah. 1sted. New Delhi: Saini printers;1980:188-190

18. Jurjani I. Zakheerae Khawarzam Shahi (Urdu trans. by Khan AH). Vol II. Lucknow: Munshi Nawal Kishore; 1903: 606-609.

19. Razi ABZ. Al Hawi Fil Tib. Vol IX. New Delhi: CCRUM; 2001: 71-110

20. Kabeeruddin S. Al Akseer. Vol II. New Delhi: Ejaz Publishing House; 2003: 1397-1401.

21. National Formulary of Unani medicine, Government of India, Ministry of AYUSH. Volume 1. Page 304.

22. 22.Tajuddin, Shamshad Ahmad,Abdul Latif,Iqbal Ahmad Qasmi and Kunwar Mohammad Yusuf Amin . An experimental study of sexual function improving effect of Myristica fragrans Houtt. (nutmeg). BMC Complementary and Alternative Medicine The official journal of the International Society for Complementary Medicine Research (ISCMR)2005 5:16 DOI: 10.1186/1472-6882-5-16

23. Mokhtar Mokhtari, Esfandiar Sharifi, Adel Daneshi. Effects of Hydro-alcoholic Extract of Red Dried Stigmas of Crocus sativus L. Flowers (saffron) on the Levels of Pituitary-ovary Hormones and Folliculogenesis in Rats, International journal of fertility \&sterility, Vol 3, No 4, Feb-Mar 2010, Pages: 185-190. 